\title{
Species differences in courtship acoustic signals among five Lake Malawi cichlid species (Pseudotropheus spp.)
}

\author{
M. C. P. Amorim*†, J. M. Simõesł, P. J. Fonsecał \\ AND G. F. TuRner $\S$ \\ *Unidade de Investigação em Eco-Etologia, ISPA, Rua Jardim do Tabaco 34, 1149-041 \\ Lisboa, Portugal, \$Departamento de Biologia Animal e Centro de Biologia Ambiental, \\ Faculdade de Ciências da Universidade de Lisboa. Bloco C2 Campo Grande, \\ 1749-016 Lisboa, Portugal and \$Department of Biological Sciences, \\ University of Hull, HU6 7RX, U.K.
}

(Received 16 April 2007, Accepted 13 December 2007)

\begin{abstract}
Male courtship acoustic signals from five Lake Malawi cichlid fish species of the Pseudotropheus zebra complex were recorded and compared. Sounds made by males of P. zebra, Pseudotropheus callainos and the undescribed species known as Pseudotropheus 'zebra gold' from Nkhata Bay, and Pseudotropheus emmiltos and Pseudotropheus faizilberi from Mphanga Rocks, differed significantly in the number of pulses and in pulse period. The largest differences in acoustic variables were found among the sympatric Mphanga Rocks species that, in contrast to the other three species, show relatively minor differences in male colour and pattern. These findings suggest that interspecific mate recognition is mediated by multimodal signals and that the mass of different sensory channels varies among sympatric species groups. This study also showed that sound peak frequency was significantly negatively correlated with male size and that sound production rate increased significantly with courtship rate.

(C) 2008 The Authors

Journal compilation (C) 2008 The Fisheries Society of the British Isles
\end{abstract}

Key words: acoustic communication; courtship; mate choice; P. zebra complex; reproductive isolation; sound production.

\section{INTRODUCTION}

Cichlids from the African Great Lakes have undergone some of the fastest and most extensive adaptive radiations among vertebrates (Turner, 1999; Albertson et al., 2003). From Lake Malawi alone, at least 450-600 endemic species have been recorded (Genner et al., 2004). Most of these species are believed to have arisen within the lake catchment within a relatively short period of time, estimated at between 700000 and 4 million years (Turner, 1999; Genner et al., 2007). Many authors have proposed that sexual selection driven by female choice acting on male courtship colours may be a significant influence on the

$\uparrow$ Author to whom correspondence should be addressed. Tel.: +351 218811700; fax: +351 218860954; email: amorim@ispa.pt 
rapid speciation of these fishes (Dominey, 1984; McKaye, 1991; Genner \& Turner, 2005). Visual cues were found to be relevant for interspecific mate recognition (Knight \& Turner, 1999; Jordan et al., 2003), but recent studies have pointed out that chemical (Plenderleith et al., 2005) and acoustic (Amorim et al., 2004) signals may also be important.

The recognition of species-specific acoustic signals can promote reproductive isolation and influence speciation processes in sympatric species (Ryan \& Rand, 1993; Wells \& Henry, 1998). Species recognition based on mating acoustic signals has been suggested for several teleosts (Crawford et al., 1997; Amorim et al., 2004) and was verified in damselfishes (Pomacentridae) (Myrberg et al., 1978; Spanier, 1979). Males of several African cichlids are known to produce sounds during courtship (Lobel, 1998; Amorim et al., 2004; Amorim, 2006). A preliminary study by Amorim et al. (2004) found statistically significant differences between some variables of the sounds produced in the early stage of courtship by males of three closely related species from Lake Malawi, Pseudotropheus zebra (Boulenger, 1899), Pseudotropheus 'zebra gold' (Ribbink et al., 1983) and Pseudotropheus callainos Stauffer \& Hert, 1992. If these differences are detected by females and influence mating decisions, acoustic communication may have an important role in the evolution of reproductive isolation and consequently on the impressive rate of speciation of these fishes.

In the present study, male courtship sounds of five Pseudotropheus species from Lake Malawi are compared: three sympatric species ( $P$. zebra, $P$. 'zebra gold' and $P$. callainos) exhibit distinct colours and patterns, while the other two species [Pseudotropheus emmiltos (Stauffer, Bowers, Kellogg \& McKaye, 1997) and Pseudotropheus fainzilberi Staeck, 1976] inhabiting another region in the lake are less divergent in their appearance. It is predicted that if species differences in courtship sounds are important in assortative mating, then acoustic signals will be more divergent among sympatric species that differ less in visual cues, such as in $P$. emmiltos and $P$. fainzilberi.

\section{MATERIALS AND METHODS}

\section{EXPERIMENTAL ANIMALS}

The study species belong to the P. zebra complex, one of the most-species rich mbuna cichlid groups endemic to Lake Malawi. These are also classed as members of the subgenus Maylandia, also known by the junior synonym Metriaclima (Stauffer et al., 1997). Males of this species complex are similar in morphological traits but differ in their breeding colours (Fig. 1). Pseudotropheus zebra, P. callainos and the undescribed species $P$. 'zebra gold' co-occur in Nkhata Bay (Fig. 1), on the western shore of Lake Malawi $\left(11^{\circ} 36^{\prime} \mathrm{N} ; 34^{\circ} 17^{\prime} \mathrm{E}\right)$ in reproductive isolation (van Oppen et al., 1998). Pseudotropheus zebra males are blue with black vertical bars, $P$. callainos males are blue without bars and $P$. 'zebra gold' males are yellow with brown vertical bars. At Mphanga Rocks $\left(10^{\circ} 45^{\prime} \mathrm{S} ; 34^{\circ} 67^{\prime} \mathrm{E}\right)$ off the north-western shore of the lake (Fig. 1), P. emmiltos and $P$. fainzilberi co-occur sympatrically. Males of both species are blue with dark vertical bars, but differ in smaller details of their breeding colours: P. emmiltos males have bright orange-red dorsal fins, while $P$. fainzilberi have blue dorsal fins with prominent black horizontal bands.

Populations of the two sympatric groups do not differ in the degree of sympatry or relatedness. All three populations at Nkhata Bay are fully sympatric, as are both at 


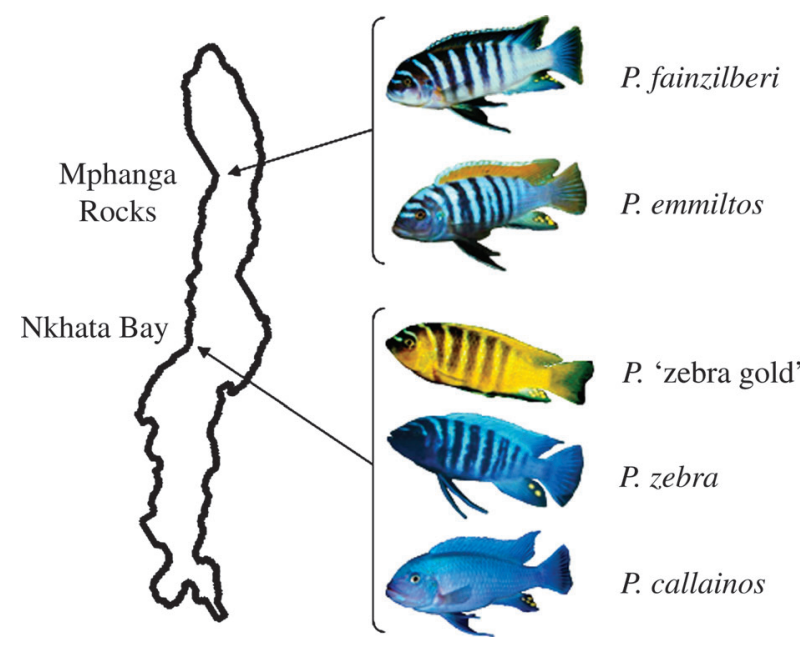

FIG. 1. Comparison of interspecific differences of male courtship acoustic signals was carried out using five species from the northern-west part of Lake Malawi. Pseudotropheus fainzilberi and Pseudotropheus emmiltos are native to Mphanga Rocks and males are blue with black vertical bars and differ mainly in the colour of the dorsal fin. Pseudotropheus 'zebra gold', Pseudotropheus zebra and Pseudotropheus callainos are found at Nkhata Bay. Males from the last three species differ more extensively in their courtship colour, with $P$. 'zebra gold' exhibiting brown vertical bars on a yellow background, $P$. zebra black vertical bars on a blue background, while $P$. callainos are plain blue.

Mphanga Rocks. Although the study species at Nkhata Bay show microhabitat preferences, including some depth preference, substantial overlap in breeding ranges of all three species have been demonstrated (van Oppen et al., 1998). Similarly, at Mphanga Rocks, the depth range of $P$. fainzilberi was fully contained within that of P. emmiltos, although individuals of the latter species were found at greater depths than those of the former (pers. obs.). Phylogenetic relationships of the study taxa have not been fully resolved. Mitochondrial DNA studies of mbuna populations have typically shown poor phylogenetic resolution, with extensive sharing of polymorphisms even between members of different genera. Genome-wide surveys of DNA polymorphisms (AFLPs) have shown that all of the Pseudotropheus (Maylandia) complex populations from the northern half of the lake (like the five taxa used in the present study) are very closely related (Allender et al., 2003).

Males defend territories to which they try to attract females to spawn with by means of a series of stereotyped visual displays (Baerends \& Baerends van Roon, 1950), acoustic signals (Amorim et al., 2004) and chemical cues (Plenderleith et al., 2005). During spawning, females take both eggs and sperm into their mouth, where the eggs are fertilized, and leave the male territory to mouthbrood in quiet shelters for up to 3 weeks. Each group of the studied sympatric species mate assortatively in the laboratory (Knight et al., 1998; Plenderleith et al., 2005), indicating that reproductive isolation can be maintained by direct mate choice alone.

All fishes used were first generation laboratory stock (c. 200 adults per species), bred from parents collected at Nkhata Bay and Mphanga Rocks. Fishes were kept in 2201 tanks in a 55001 re-circulation system, with a density of $c$. 40 fishes per tank, under a 12L:12D regime and fed on a mixture of commercial fish flakes and pellets. Water temperature was kept at $25-27^{\circ} \mathrm{C}$.

\section{SOUND RECORDING AND ANALYSIS}

Pseudotropheus spp. males were recorded in experimental tanks (Nkhata Bay species: two tanks $1200 \times 600 \times 450 \mathrm{~mm}$ high; Mphanga Rocks: four tanks $(1000 \times 500 \times 400 \mathrm{~mm}$ 
high) divided into three compartments by two opaque removable partitions. Lateral compartments ( $300 \mathrm{~mm}$ wide) held a single male, with a terracotta pot that served as refuge and as a prospective spawning site, and the central compartment (c. $400 \mathrm{~mm}$ wide) housed five to seven females throughout the experiment. Each tank housed a single species. Recording tanks were placed on top of thick layers of rock-wool that insulated tanks from external noise transmitted through floor vibrations. Males were left to acclimatize for a minimum of $12 \mathrm{~h}$ before the start of recording trials.

Approximately 5-10 min prior to the start of a recording session all electric appliances (aeration, filters and lights) were switched off. Each recording session started when one of the opaque partitions was removed, allowing the focal male free access to females for $20 \mathrm{~min}$, after which males were placed back in their lateral compartment. Each male was recorded in a maximum of three sessions. Once recordings were complete, the tested subject was weighed (mass, $M$ ), measured (standard length, $L_{\mathrm{S}}$ ), returned to a stock tank and replaced with another male of the same species. Males were identified by electronic tags that were previously inserted in their abdominal cavity or by natural marks such as number of egg spots in the anal fin.

Sounds were recorded using two High Tech 94 SSQ hydrophones (High Tech Inc.,

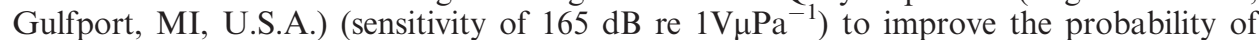
recording sounds close to the sound emitter, and a Pioneer DVD Recorder DVR-3100 (Tokyo, Japan) (sampling frequency $48 \mathrm{kHz}, 24$ bit resolution). This audio chain had a flat frequency response up to $6 \mathrm{kHz} \pm 1.5 \mathrm{~dB}$. Sounds were analysed with Adobe Audition 2.0 (Adobe Systems, Inc.) and Raven 1.2.1 for Windows (Cornell Lab of Ornithology). Acoustic analysis only considered sounds associated with the behaviour quiver that is characteristic of the early stages of courtship (Baerends \& Baerends van Roon, 1950). Moreover, only sounds that showed a clear structure, typically registered at a distance of 1-2 total lengths of the focal fish, were analysed. Recorded sounds could be attributed to the subject males because their intensity varied with distance from the hydrophone and were consistently associated with particular courtship displays, such as quiver and circle (Amorim et al., 2004).

The following acoustic variables were analysed (Fig. 2; Amorim et al., 2004): sound duration (ms); number of pulses in a sound; mean pulse period (average peak-to-peak interval between consecutive pulses, ms). In addition, two frequency peaks at $c .150 \mathrm{~Hz}$ (PF1) and at $450 \mathrm{~Hz}$ region (PF2) were measured (Fig. 2). Temporal features were measured from oscillograms and peak frequencies from power spectra based on 2048 point FFT with a Hamming window applied.

A total of $12 P$. 'zebra gold', $12 P$. zebra, $13 P$. callainos, $13 P$. fainzilberi and 14 $P$. emmiltos adult males were recorded and analysed (Table I provides details on male size and number of sounds recorded per male).

\section{BEHAVIOUR RECORDING AND ANALYSIS}

During sound recording sessions male courtship behaviour was also tallied. Male courtship behaviour includes the behavioural patterns quiver, dart, lead-swim and circle (Baerends \& Baerends van Roon, 1950; Amorim et al., 2004). Quiver rate (number $\min ^{-1}$ ), courtship rate (total number of courtship activities min ${ }^{-1}$ ) and sound production rate (number $\min ^{-1}$ ) were considered for each recording session.

\section{DATA ANALYSIS}

One-way ANOVA was used to compare differences among species in the duration, number of pulses and pulse period of 'quiver' sounds. The square root transformation was applied to the number of pulses to meet the ANOVA assumptions of normality and homoscedasticity. Comparison among species for variables other than sound frequency were not controlled for the effect of $L_{\mathrm{S}}$ because the variables were not significantly correlated with $L_{\mathrm{S}}$ (Spearman rank correlation, $r_{\mathrm{s}}, P>0.05$; Amorim et al., 


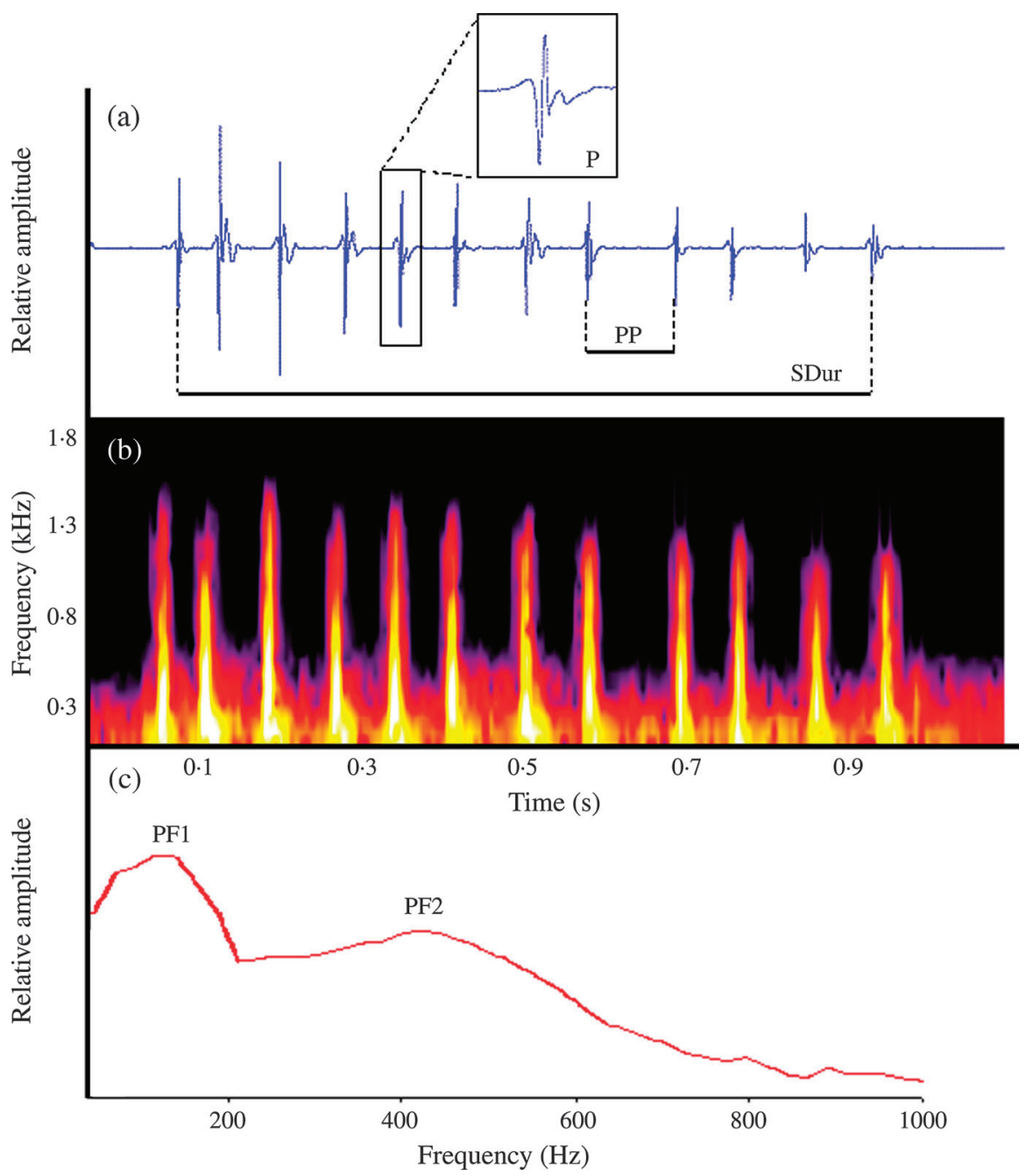

FIG. 2. (a) Oscillogram, (b) sonogram and (c) power spectrum of a typical courtship sound emitted by males of Pseudotropheus spp. (P. fainzilberi in the example) during 'quivering'. Some of the acoustic variables measured are depicted in the figure: number of pulses ( $\mathrm{P}$ is an example of a pulse), sound duration (SDur), pulse period (PP), and peak frequency 1 (PF1) and 2 (PF2). Relative amplitude is shown in the $y$-axis of the oscillogram and the power spectrum.

2004). Because the dominant sound frequency is dependent on male size (Amorim et al., 2004), however, an ANCOVA was conducted to test differences among species for the frequency variables PF1 and PF2, using $L_{\mathrm{S}}$ as a covariate. The assumption of slope parallelism was tested before carrying out the above ANCOVA models (PF1 and PF2, both d.f. $=4,54, P>0 \cdot 05)$.

Spearman rank correlation, $r_{\mathrm{s}}$, was used to test whether quiver rate and courtship rate were related to sound production rate in each species. In addition, sound production rate was compared among species with ANOVA. Sound production rate was $\log _{10}$ $(x+1)$ transformed to meet the ANOVA assumptions. An average of two recording sessions were considered per male. All statistical analyses were conducted using Statistica 7.1 for Windows (StatSoft, Inc.). 


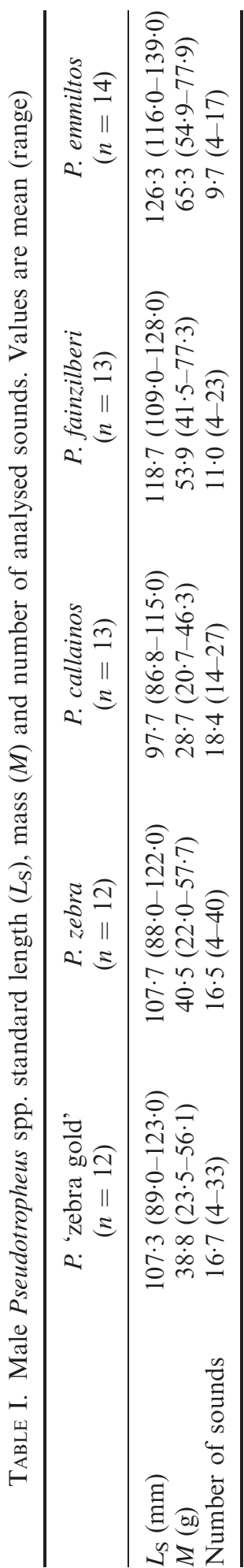




\section{RESULTS}

Sound production by females was never observed during courtship interactions in any species. Males courted females mostly by repeated sequences of darting and quivering. During quivering, males from the five studied species commonly produced low-frequency pulsed sounds (Table II and Fig. 3). Quivering behaviour could last longer than sound production especially after the male emitted a few sounds.

When comparing all five Pseudotropheus species, no significant differences in sound duration were found (ANOVA, d.f. $=4$, 59, $P>0.05$; Fig. 4). Sounds lasted c. $700 \mathrm{~ms}$ in all species. The number of pulses differed significantly among species (ANOVA, d.f. $=4,59, P<0.001$ ), with $P$. emmiltos producing the greatest number of pulses per sound (mean $=16 \cdot 3$ pulses), followed by $P$. 'zebra gold' (mean $=12 \cdot 7$ ) and by the three other species (means $=8 \cdot 6-9 \cdot 5$; Fig. 4). Pulse period also showed significant interspecific differences (ANOVA, d.f. $=4,59, P<0.001)$ with $P$. emmiltos producing pulses with significantly shorter periods, i.e. at a faster rate than the remaining species, followed by $P$. 'zebra gold' and P. callainos, and then by $P$. zebra and P. fainzilberi (Fig. 4). Pseudotropheus 'zebra gold' and $P$. callainos did not differ significantly in pulse period, nor did P. zebra and P. fainzilberi (Fig. 4). Mean pulse period was $c .50 \mathrm{~ms}$ for $P$. emmiltos, $70 \mathrm{~ms}$ for $P$. 'zebra gold' and $P$. callainos, and near $90 \mathrm{~ms}$ for the remaining species. Neither PF1 (ANCOVA, d.f. $=4,58, P>0.05$ ) nor PF2 (ANCOVA, d.f. $=4,58, P>0.05)$ differed among species after controlling for the effect of male size (Fig. 4). Male $L_{\mathrm{S}}$ decreased significantly PF1 (ANCOVA, covariate $L_{\mathrm{S}}$, d.f. $=4,58, P<0.05$ ) and especially PF2 (ANCOVA: covariate $L_{\mathrm{S}}$, d.f. $\left.=4,58, P<0 \cdot 001\right)$.

When comparing the two groups of sympatric species, the largest differences in acoustic variables were found among the Mphanga Rocks species both for number of pulses and pulse period. The largest mean pair-wise differences in the acoustic variables of the Nkhata bay group were found between $P$. 'zebra gold' and $P$. zebra that typically differed by 4 pulses and $21 \mathrm{~ms}$ in pulse period. In contrast, mean differences between Mphanga Rocks species were almost double than the previous and amounted to 7 pulses and $38 \mathrm{~ms}$ in pulse period.

Sound production rate was positively correlated with both quiver rate $(n=$ $12-29, P<0.001)$ and total courtship rate $(n=12-29, P<0.001)$ in all five studied species. Sound production rate was significantly higher in $P$. emmiltos than in the other four species (ANOVA, d.f. $=4,45, P<0.001$ ), with $P$. emmiltos producing on average 1.4 sounds $\mathrm{min}^{-1}$ and the remaining species $0 \cdot 7-0 \cdot 8$ sounds $\min ^{-1}$.

\section{DISCUSSION}

The present study demonstrated the existence of interspecific differences in the courtship sounds of members of the P. zebra complex that may allow species recognition. Males from the five species studied, including $P$. fainzilberi and $P$. emmiltos which were studied for the first time, produced low frequency pulsed sounds that differed in the number and rate of pulse production. These sounds were produced mostly when males were quivering to females. 


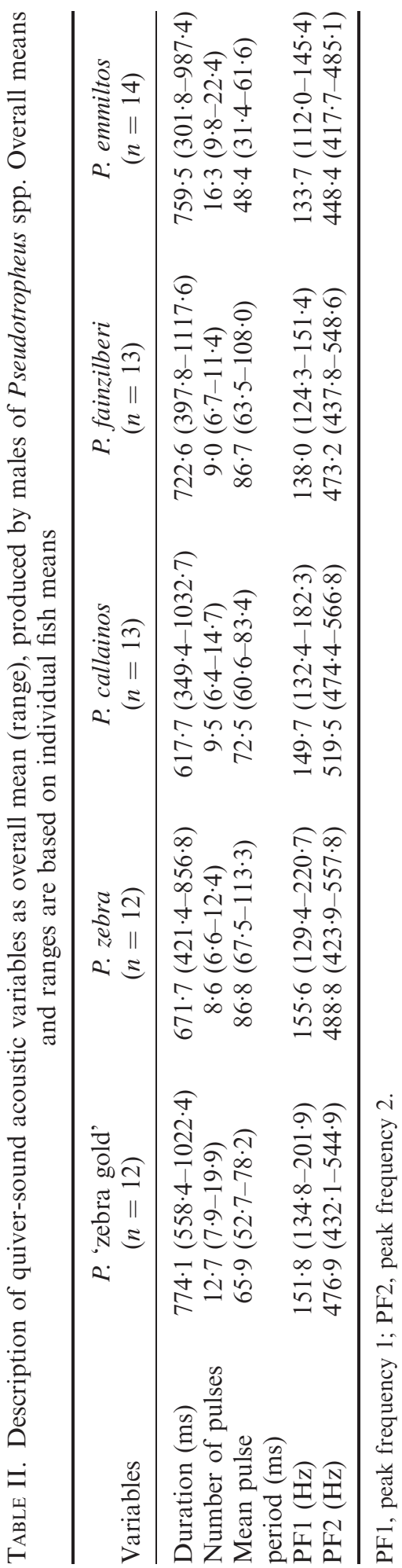




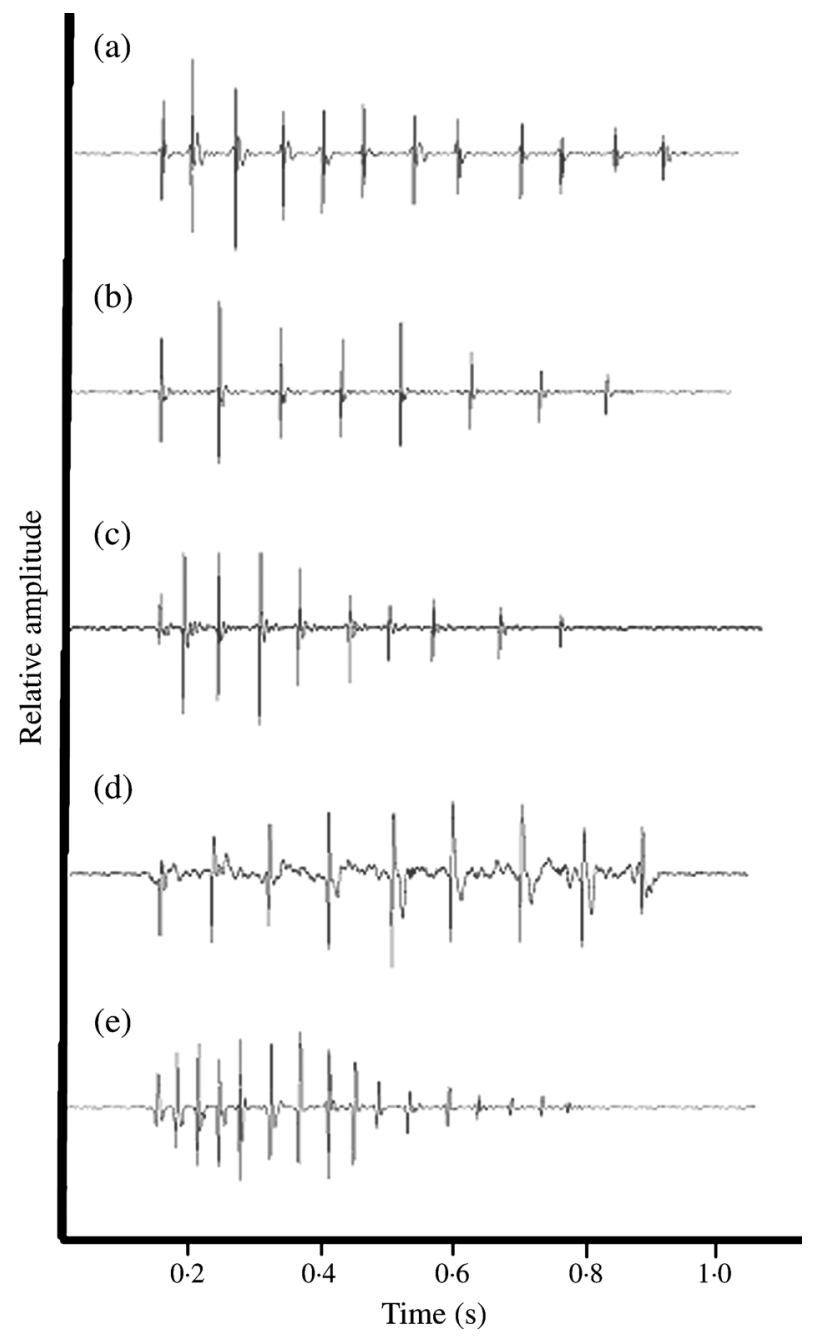

FIG. 3. Oscillograms of typical courtship sounds emitted by males of (a) Pseudotropheus 'zebra gold', (b) Pseudotropheus zebra, (c) Pseudotropheus callainos, (d) Pseudotropheus fainzilberi and (e) Pseudotropheus emmiltos. Differences among species and especially in P. fainzilberi and P. emmiltos can be observed in number of pulses and in the pulse period. Sound amplitude (relative amplitude) in oscillograms is not absolute and comparisons of this variable can only be made among pulses of the same sound.

The Nkhata Bay species differed in number of pulses and pulse period, with $P$. 'zebra gold' emitting longer sounds and with a higher number of pulses than P. zebra and P. callainos, and P. zebra exhibiting lower pulse rates (i.e. longer pulse periods). The present findings are consistent with the earlier study by Amorim et al. (2004) who found that $P$. 'zebra gold' males produced sounds with more pulses than $P$. callainos did.

According to the a priori hypothesis, P. fainzilberi and P. emmiltos from Mphanga Rocks presented larger differences in pulse number and period than the Nkhata Bay species, which showed greater differences in male colour. 

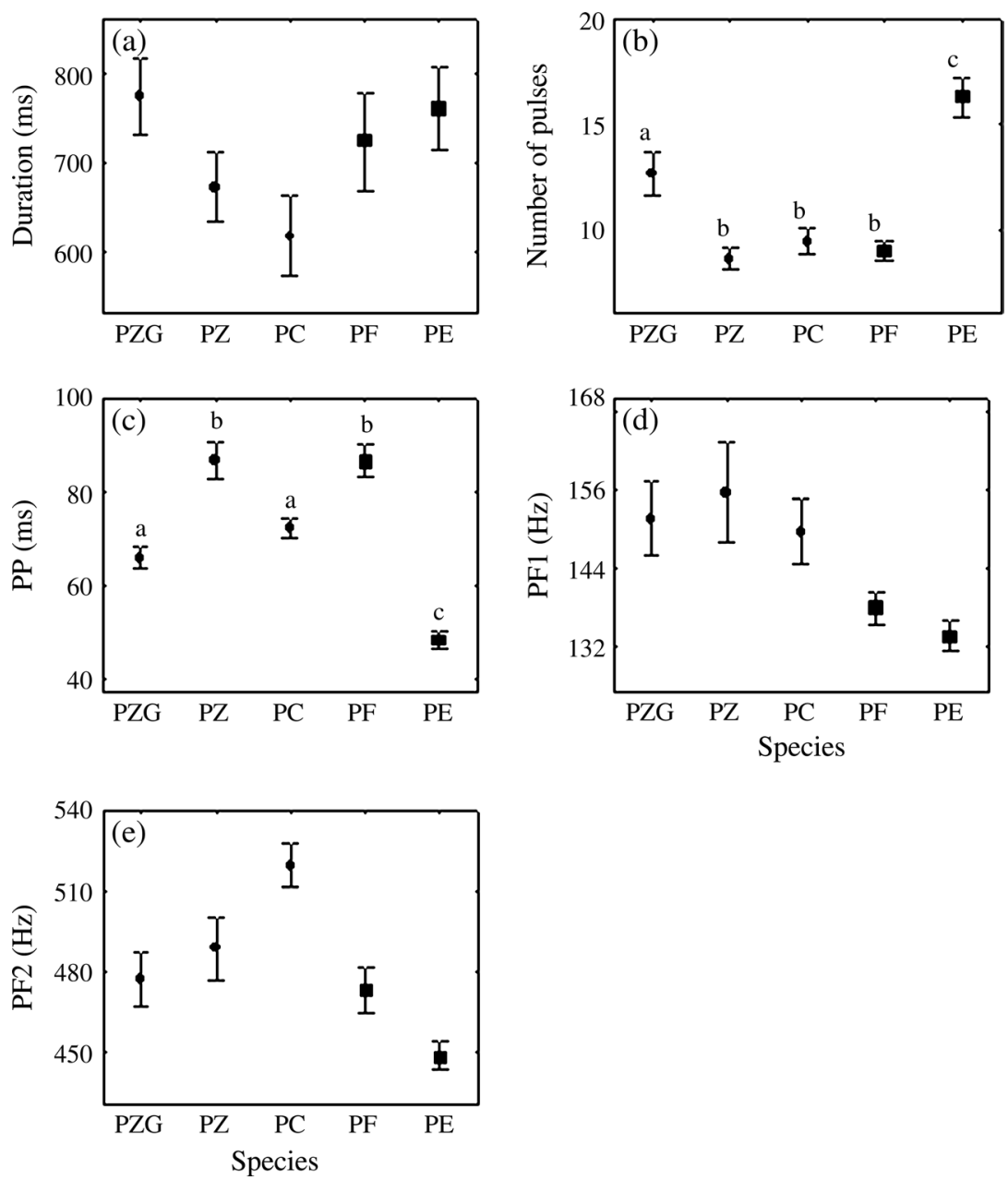

FIG. 4. Comparison of courtship mean \pm s.E. sound variables: (a) duration, (b) number of pulses, (c) pulse period (PP), (d) peak frequency 1 (PF1) and (e) peak frequency 2 (PF2) among the five species: Pseudotropheus 'zebra gold' (PZG), Pseudotropheus zebra (PZ), Pseudotropheus callainos (PC), Pseudotropheus fainzilberi (PF) and Pseudotropheus emmiltos (PE) (O, Nkhata Bay species; Mphanga Rock species). Sample sizes were $n(\mathrm{PZG})=n(\mathrm{PZ})=12 ; n(\mathrm{PC})=n(\mathrm{PF})=13 ; n(\mathrm{PE})=$ 14. Significant differences for pair-wise comparisons (Tukey test, $P<0.05$ ) are indicated by different lower case letters. Notice that the largest differences in acoustic variables within bays were found among the Mphanga Rocks species.

Similarly, Nelissen (1978) has found that the number of colour patterns and sound types was inversely proportional in six Tanganyikan cichlid fishes.

In Pseudotropheus spp., as well as in other fishes, mate recognition and evaluation may involve the integration of different sensory components (Candolin, 2003). Acoustic signals of teleosts are thought to be part of a multimodal signal system as they are usually produced in tight association with particular visual displays (Amorim et al., 2004) and because playback of sound alone often fails to elicit a response unless the sounds are accompanied by visual stimuli (Ladich, 2004). This study suggests that the acoustic sensory channel may have more 
weight in the multimodal courtship displays of the Mphanga Rocks species than in the Nkhata Bay ones. Consistent with this suggestion, P. fainzilberi and $P$. emmiltos failed to mate assortatively in laboratory mating trials when females had access only to visual signals from males (Plenderleith et al., 2005).

Reports of sound production in other cichlid species indicate that they produce only one type of sound during courtship (Amorim, 2006), typically associated with the quivering behaviour, an early courtship behaviour when mate recognition is likely to occur (Amorim et al., 2004; Ripley \& Lobel, 2005). Other African cichlid species that are often closely related and sympatric also differ in the pulse number, pulse rate and in sound duration (Lobel, 2001; Rice \& Lobel, 2004). These consistent differences in temporal patterning in cichlid courtship sounds suggest that these signal variables may play a role in interspecific recognition in sympatric species of cichlids, including members of the $P$. zebra complex. In fishes as in other taxa, temporal information is important for interspecific and intraspecific communication, such as species recognition (Winn, 1964; Honda-Sumi, 2005). In other fishes, e.g. Pomacentridae, several species of the genus Stegastes are sympatric and male courtship chirps show species-specific duration, number of pulses and pulse repetition rate (Myrberg et al., 1978; Lobel \& Mann, 1995). Playback experiments have confirmed that the number of pulses and pulse rate can promote species-specific recognition (Myrberg et al., 1978; Spanier, 1979), demonstrating that species recognition based on acoustic cues occurs in fishes. These experiments, however, did not demonstrate that male chirps were effective in species isolation, as only the male response to playbacks was measured.

Premating mechanisms among sympatric species are essential for the maintenance of reproductive isolation in recently evolved species where hybridization is still possible. Divergent mating signals can be effective mechanisms in preventing hybridization (Qvarnström et al., 2006) and closely related species may use different sensory channels to recognize conspecific mates (Rafferty \& Boughman, 2006). Recent studies involving members of the P. zebra complex have emphasized the possible use of different sensory channels in the maintenance of reproductive isolation among sympatric species and allopatric forms. Choice experiments where olfactory and possibly also acoustic communication were prevented suggested that male colour, shape and pattern are the most important cues for mate recognition in some species (Jordan et al., 2003; Kidd et al., 2006). In other P. zebra complex species, however, olfactory cues must be present for preference for conspecific males to occur (Plenderleith et al., 2005). Up to present there is no study that investigated the contribution of the acoustic channel for mate recognition by species of this rich group of Lake Malawi cichlids. Nevertheless, in view of the diversity of acoustic signals it is possible that different species may use this sensory channel balanced with the visual and olfactory ones in interspecific and intraspecific recognition and mate choice.

Notably, other sound features did not differ among the Pseudotropheus species but presented intraspecific variation associated with male traits, suggesting that some sound variables of signalling males might contain information about species identity while others could be used in the evaluation of conspecific males and hence in intraspecific mate choice. Sound peak frequency, in particular PF2, was negatively correlated with fish size in all studied species with PF2 
decreasing on average by c. $2 \cdot 2 \mathrm{~Hz}$ per $\mathrm{mm}$ increase in male $L_{\mathrm{S}}$. This inverse relation between dominant frequency and fish size is common in cichlids (Rowland, 1978; Amorim et al., 2003) and in other fishes (Myrberg et al., 1993), and may be used by females as a cue in mate choice. For example, female damselfishes (Pomacentridae) prefer sounds of lower frequency that, as in Pseudotropheus spp. males, indicate a larger male body size (Myrberg et al., 1986). The rate of sound production, that was positively correlated with quiver frequency and total courtship frequency in all five Pseudotropheus species, could also be used by females for assessing the condition and motivation of a conspecific male. Females of several taxa commonly have a preference for males that show a higher courtship display activity, as it may be related to higher genetic quality or other preferred male traits (Svensson et al., 2004).

The present results suggest that different features of the courtship calls may contain information about species identity and intraspecific differences in traits, such as size, relevant to mate choice. In particular, the number of pulses and pulse period of courtship sounds are species-specific and these acoustic cues, in conjunction with visual and chemical information, may promote reproductive isolation. Finally, the present findings suggest that the weight of different sensory channels used in interspecific mate recognition may vary among sympatric species assemblages.

This study was supported by a grant POSI SFRH/BPD/14570/2003 of FCT and the pluriannual programmes (UI\&D 331/94)/FCT (M.C.P.A.) and POCTI-ISFL-4-329/ FCT (P.J.F.). The Treaty of Windsor funded mutual visits between the Portuguese and English teams. We are grateful to I. Duarte for assistance during some recordings, and to N. Wreathall, A. Smith, K. Woodhouse and P. Nichols for help with logistics and fish maintenance.

\section{References}

Albertson, R. C., Streelman, J. T. \& Kocher, T. D. (2003). Directional selection has shaped the oral jaws of Lake Malawi cichlid fishes. Proceedings of the National Academy of Sciences of the United States of America 100, 5252-5257.

Allender, C. J., Seehausen, O., Knight, M. E., Turner, G. F. \& Maclean, N. (2003). Divergent selection during speciation of Lake Malawi cichlid fishes inferred from parallel radiations in nuptial coloration. Proceedings of the National Academy of Sciences of the United States of America 100, 14074-14079.

Amorim, M. C. P. (2006). Diversity of sound production in fish. In Communication in Fishes, Vol. I (Ladich, F., Collin, S. P., Moller, P. \& Kapoor, B. G., eds), pp. 71-104. Enfield, NH: Science Publishers.

Amorim, M. C. P., Fonseca, P. J. \& Almada, V. C. (2003). Sound production during courtship and spawning of the cichlid Oreochromis mossambicus: male-female and male-male interactions. Journal of Fish Biology 62, 658-672. doi: 10.1046/j.00221112.2003.00054.x

Amorim, M. C. P., Knight, M. E., Stratoudakis, Y. \& Turner, G. F. (2004). Differences in sounds made by courting males of three closely related Lake Malawi cichlid species. Journal of Fish Biology 65, 1358-1371. doi: 10.1111/j.0022-1112.2004. 00535.x

Baerends, G. P. \& Baerends van Roon, J. M. (1950). An introduction to the study of the ethology of cichlid fishes. Behaviour 1 (Suppl.), 1-235.

Candolin, U. (2003). The use of multiple cues in mate choice. Biological Reviews 78, $575-595$. 
Crawford, J. D., Cook, A. P. \& Heberlein, A. S. (1997). Bioacoustic behavior of African fishes (Mormyridae): potential cues for species and individual recognition in Pollimyrus. The Journal of the Acoustical Society of America 102, 1200-1212.

Dominey, W. J. (1984). Effects of sexual selection and life history on speciation: species flocks in African cichlid fish and Hawaiian Drosophila. In Evolution of Fish Species Flocks (Echelle, A. A. \& Kornfield, I., eds), pp. 231-249. Orono, ME: University of Maine Press.

Genner, M. J. \& Turner, G. F. (2005). The mbuna cichlids of Lake Malawi: a model for rapid speciation and adaptive radiation. Fish and Fisheries 6, 1-34. doi: 10.1111/ j.1467-2679.2005.00173.x

Genner, M. J., Seehausen, O., Cleary, D. F. R., Knight, M. E., Michel, E. \& Turner, G. F. (2004). How does the taxonomic status of allopatric populations influence species richness within African cichlid fish assemblages? Journal of Biogeography 31, 93-102. doi: 10.1046/j.0305-0270.2003.00986.x

Genner, M. J., Seehausen, O., Lunt, D. H., Joyce, D. A., Carvalho, G. R., Shaw, P. W. \& Turner, G. F. (2007). Age of cichlids: new dates for ancient lake fish radiations. Molecular Biology and Evolution 24, 1269-1282. doi: 10.1093/molbev/msm050

Honda-Sumi, E. (2005). Difference in calling song of three field crickets of the genus Teleogryllus: the role in premating isolation. Animal Behaviour 69, 881-889.

Jordan, R., Kellogg, K., Juanes, F. \& Stauffer, J. Jr (2003). Evaluation of female mate choice cues in a group of Lake Malawi mbuna (Cichlidae). Copeia 2003, 181-186.

Kidd, M. R., Danley, P. D. \& Kocher, T. D. (2006). A direct assay of female choice in cichlids: all the eggs in one basket. Journal of Fish Biology 68, 373-384. doi: $10.1111 /$ j.1095-8649.2005.00896.x

Knight, M. E. \& Turner, G. F. (1999). Reproductive isolation among closely related Lake Malawi cichlids: can males recognise conspecific females by visual cues? Animal Behaviour 58, 761-768.

Knight, M. E., Turner, G. F., Rico, C., van Oppen, M. J. H. \& Hewitt, G. M. (1998). Microsatellite paternity analysis on captive Lake Malawi cichlids supports reproductive isolation by direct mate choice. Molecular Ecology 7, 1605-1610. doi: 10.1046/j.1365-294x.1998.00478.x

Ladich, F. (2004). Sound production and acoustic communication. In The Senses of Fish Adaptations for the Reception of Natural Stimuli (von der Erude, G., Mogdans, J. \& Kapoor, B. G., eds), pp. 210-230. New Delhi: Narosa Publishing House.

Lobel, P. S. (1998). Possible species specific courtship sounds by two sympatric cichlid fishes in Lake Malawi, Africa. Environmental Biology of Fishes 52, 443-452.

Lobel, P. S. (2001). Acoustic behavior of cichlid fishes. Journal of Aquariculture \& Aquatic Sciences 9, 167-186.

Lobel, P. S. \& Mann, D. (1995). Spawning sounds of the damselfish, Dascyllus albisella (Pomacentridae), and relationship to male size. Bioacoustics 6, 187-198.

McKaye, K. R. (1991). Sexual selection and the evolution of the cichlid fishes of Lake Malawi, Africa. In Cichlid Fishes: Behaviour, Ecology and Evolution (Keenleyside, M. H. A., ed.), pp. 241-257. London: Chapman \& Hall.

Myrberg, A. A. Jr., Spanier, E. \& Ha, S. J. (1978). Temporal patterning in acoustical communication. In Contrasts in Behaviour (Reese, E. S. \& Lighter, F. J., eds), pp. 137-179. New York: John Wiley \& Sons.

Myrberg, A. A. Jr., Mohler, M. \& Catala, J. (1986). Sound production by males of a coral reef fish (Pomacentrus partitus): its significance to females. Animal Behaviour 24, 923-933.

Myrberg, A. A. Jr., Ha, S. J. \& Shamblott, H. (1993). The sounds of bicolor damselfish (Pomacentrus partitus): predictors of body size and a spectral basis for individual recognition and assessment. The Journal of the Acoustical Society of America 94, 3067-3070.

Nelissen, M. (1978). Sound production by some Tanganykan cichlid fishes and a hypothesis for the evolution of the $\mathrm{R}$ communication mechanisms. Behaviour 64, 137-147. 
van Oppen, M. J. H., Turner, G. F., Rico, C., Deutsch, J. C., Robinson, R. L., Genner, M. J. \& Hewitt, G. M. (1998). Assortative mating among rock-dwelling cichlid fishes supports high estimates of species richness from Lake Malawi. Molecular Ecology 7, 991-1001.

Plenderleith, M., van Oosterhout, C., Robinson, R. L. \& Turner, G. F. (2005). Female preference for conspecific males based on olfactory cues in a Lake Malawi cichlid fish. Biology Letters 4, 411-414.

Qvarnström, A., Haavie, J., Saether, S. A., Eriksson, D. \& Pärt, T. (2006). Song similarity predicts hybridization in flycatchers. Journal of Evolutionary Biology 19, 1202-1209. doi: 10.1111/j.1420-9101.2006.01140.x

Rafferty, N. \& Boughman, J. W. (2006). Olfactory mate recognition in a sympatric species pair of threespine sticklebacks. Behavioral Ecology 17, 965-970.

Ribbink, A. J., Marsh, B. A., Marsh, A. C., Ribbink, A. C. \& Sharp, B. J. (1983). A preliminary survey of the cichlid fishes of rocky habitats in Lake Malawi. South African Journal of Zoology 18, 149-310.

Rice, A. A. \& Lobel, P. S. (2004). The pharyngeal jaw apparatus of the Cichlidae and Pomacentridae: function in feeding and sound production. Reviews in Fish Biology and Fisheries 13, 433-444.

Ripley, J. L. \& Lobel, P. S. (2005). Correlation of acoustic and visual communication in the Lake Malawi cichlid Tramitichromis intermedius. Environmental Biology of Fishes 71, 389-394.

Rowland, W. J. (1978). Sound production and associated behavior in the jewel fish, Hemichromis bimaculatus. Behaviour 64, 125-136.

Ryan, M. J. \& Rand, A. S. (1993). Species recognition and sexual selection as a unitary problem in animal communication. Evolution 47, 647-657.

Spanier, E. (1979). Aspects of species recognition by sound in four species of damselfishes, genus Eupomacentrus (Pisces: Pomacentridae). Zeitschrift für Tierpsychologie 51, 301-316.

Stauffer, J. R., Bowers, N. J., Kellog, K. A. \& McKaye, K. R. (1997). A revision of the blue-black Pseudotropheus zebra (Teleostei, Cichlidae) complex from Lake Malawi, Africa, with a description of a new genus and ten new species. Proceedings of the Academy of Natural Sciences of Philadelphia 148, 189-230.

Svensson, O., Nyman, A. \& Kvarnemo, C. (2004). Costly courtship or dishonest display? Intensely displaying sand goby males have lower lipid content. Journal of Fish Biology 64, 1425-1429. doi: 10.1111/j.0022-1112.2004.00381.x

Turner, G. F. (1999). Explosive speciation of African cichlid fishes. In Evolution of Biological Diversity (Magurran, A. E. \& May, R. M., eds), pp. 217-229. Oxford: Oxford University Press.

Wells, M. M. \& Henry, C. S. (1998). Songs, reproductive isolation and speciation in cryptic species of insects. In Endless Forms. Species and Speciation (Howard, D. J. \& Berlocher, S. H., eds), pp. 217-233. New York: Oxford University Press.

Winn, H. E. (1964). The biological significance of fish sounds. In Marine Bio-acoustics, Vol. 1 (Tavolga, W. N., ed.), pp. 213-230. Oxford: Pergamon Press. 